\title{
Prediction of the Need for Surgical Intervention in Obstructive Crohn's Disease by ${ }^{18}$ F-FDG PET/CT
}

\author{
Heather A. Jacene ${ }^{1}$, Philip Ginsburg ${ }^{2,3}$, John Kwon ${ }^{2}$, Geoffrey C. Nguyen ${ }^{2,4}$, Elizabeth A. Montgomery ${ }^{5}$, \\ Theodore M. Bayless ${ }^{2}$, and Richard L. Wahl ${ }^{1}$ \\ ${ }^{1}$ Division of Nuclear Medicine, Russell H. Morgan Department of Radiology and Radiological Science, Johns Hopkins University \\ School of Medicine, Baltimore, Maryland; ${ }^{2}$ Division of Gastroenterology and Hepatology, Department of Medicine, Johns Hopkins \\ University School of Medicine, Baltimore, Maryland; ${ }^{3}$ Department of Medicine, Yale University, New Haven, Connecticut; \\ ${ }^{4}$ Department of Medicine, University of Toronto, Toronto, Ontario; and ${ }^{5}$ Department of Pathology, Johns Hopkins University School \\ of Medicine, Baltimore, Maryland
}

\begin{abstract}
We preoperatively determined the accuracy of ${ }^{18} \mathrm{~F}-\mathrm{FDG}$ PET/CT for differentiating fixed muscle hypertrophy and fibrotic stenoses from acute transmural inflammatory stenoses in patients with Crohn's disease (CD) scheduled to undergo surgical resection for obstructive symptoms. Methods: Seventeen patients with known CD prospectively underwent ${ }^{18} \mathrm{~F}$-FDG PET/CT before already-planned surgery for obstructive symptoms. Image interpretation was by consensus of 2 readers with knowledge of patient participation in the study but not of other clinical history. Lesions were qualitatively graded on a 5-point scale for the presence of increased ${ }^{18} \mathrm{~F}-\mathrm{FDG}$ uptake consistent with active inflammation. Maximum lean standardized uptake value (SUL $L_{\max }$ ) was determined for lesions scored 1 or more. Imaging results were compared with the pathologic grading of inflammation and predominant histopathologic subtype for each patient's surgical specimen, whether mainly inflammation, fibrosis, or muscle hypertrophy. Results: Thirteen of the 17 patients underwent surgery (median, $28 \mathrm{~d}$ after PET/CT; range, 2-148 d), and 12 of these 13 had histopathologic correlation. Despite the predominant histopathologic subtype (inflammation, 5; fibrosis, 4; and muscle hypertrophy, 3), acute and chronic inflammation, fibrosis (median, 50\%; range, 40\% -90\%), and muscle hypertrophy (median, 20-fold thickening; range, 9- to 40-fold thickening) were found in all patients. SUL $L_{\max }$ was significantly higher in severe than in mild-to-moderate chronic inflammation $(8.2 \pm 2.8$ vs. $4.7 \pm 2.5, P=0.04)$. No patient with predominantly fibrosis or muscle hypertrophy $(n=7)$ had an SUL $_{\max }$ greater than 8 . Visually, 10 of 12 patients on PET/CT were considered to have active inflammation of the bowel. Conclusion: Patients with CD who undergo surgery for obstructive symptoms have histopathologically mixed findings of inflammation, fibrosis, and muscle hypertrophy. Qualitative PET interpretations were quite sensitive, but additional semiquantitative analyses using $S U L_{\max }$ helped identify patients with active inflammation. This information may be beneficial for referring gastroenterologists considering medical therapy versus surgery for patients with $C D$ who present with obstructive symptoms.
\end{abstract}

Received Apr. 24, 2009; revision accepted Jul. 21, 2009.

For correspondence or reprints contact: Richard L. Wahl, $601 \mathrm{~N}$.

Caroline St., JHOC 3223, Baltimore, MD 21287.

E-mail: rwahl@jhmi.edu

COPYRIGHT @ 2009 by the Society of Nuclear Medicine, Inc.
Key Words: Crohn's disease; ${ }^{18} \mathrm{~F}-\mathrm{FDG}$; PET/CT; stricture; inflammation

J Nucl Med 2009; 50:1751-1759

DOI: 10.2967/jnumed.109.065466

C rohn's disease (CD) is a chronic, relapsing inflammatory disorder of uncertain etiology that mostly involves the small bowel or colon. Histologically, early CD is characterized by neutrophilic infiltration of the mucosa, aphthous ulcers, and noncaseating granulomas in one third of patients. Later, aphthous ulcers coalesce and lymphoid aggregates predominate in a characteristic pattern of chronic, transmural inflammation. Muscularis propria hypertrophy and fibrosis occur and contribute to the development of strictures (1). Resection specimens provide complete information on the transmural process.

On the basis of clinical-pathologic behavior, 3 subtypes of CD have been described: stricturing, penetrating, and inflammatory (or nonstricturing/nonpenetrating) (2,3). For patients with the stricturing subtype, inflammation and accompanying cytokines lead to a pattern of muscle hypertrophy and collagen production from myofibroblasts over 8-10 y. This pattern of muscle hypertrophy and collagen production results in luminal narrowing and obstruction. There may be inflammation, ulceration, or fistulization proximal to or within the stricture.

In contrast, a subset of patients with ileal CD presents with active inflammation, diarrhea, and obstruction early after diagnosis, usually in the first 2-4 y $(4,5)$. This subgroup has disease characterized mostly by inflammation, which progresses rapidly and may cause obstructive symptoms $(4,5)$.

Because the narrowing of the bowel lumen caused by acute and chronic inflammation is potentially reversible by medical therapy, differentiating the predominant cause of 
obstruction in patients with CD has important therapeutic implications. However, focal obstruction is usually due to muscle hypertrophy and constriction with circumferential fibrinous collagen deposition. There is often proximal dilation of the bowel. This is an ideal indication for surgical resection, often done laparoscopically.

Noninvasive anatomic and functional imaging modalities, including CT enteroclysis (6-9), CT enterography, ultrasound, magnetic resonance enterography, and radiolabeled white blood cell and granulocyte scintigraphy (10-19), have shown some ability to measure the extent and severity of active inflammation in $\mathrm{CD}$. Neither these techniques nor endoscopy allows complete assessment of transmural inflammation or extraluminal complications of CD. Important treatment decisions, including surgery or aggressive medical therapy, by the clinician are frequently based on clinical circumstances without imaging confirmation.

Both neutrophils (primary leukocytes of acute inflammation) and macrophages (major cells of chronic inflammation) accumulate high levels of ${ }^{18}$ F-FDG (20-22). Initial animal and human data suggest that the noninvasive imaging technique using ${ }^{18} \mathrm{~F}-\mathrm{FDG}$ and PET may help for identifying gastrointestinal inflammation (15,23-28). Combined PET/CT scanners offer more precise lesion characterization and localization $(26,27)$.

Our primary objective was to preoperatively determine the accuracy of ${ }^{18} \mathrm{~F}-\mathrm{FDG}$ PET/CT for differentiating fixed muscle hypertrophy and fibrotic stenoses from acute transmural inflammatory stenoses in patients with $\mathrm{CD}$ who were already scheduled to undergo surgery for obstructive symptoms. The responsible clinician was not aware of the results of the PET/CT research study in terms of degree of inflammation. Secondarily, we compared qualitative and quantitative assessments.

\section{MATERIALS AND METHODS}

\section{Study Design and Eligibility Criteria}

Our institutional review board approved this prospective study. Informed written consent was obtained from all patients prior to study procedures. Patients older than $18 \mathrm{y}$ with previously documented CD involving the small bowel and Vienna classification L1 (terminal ileum) or L3 (ileocolon) (29), for whom surgery was anticipated within $4 \mathrm{wk}$ for obstructing symptoms, were recruited. None had intestinal fistulas demonstrated preoperatively. Concurrent medications included antibiotics, aminosalicylates, oral prednisone, budesonide, azathioprine or 6-mercaptopurine, and methotrexate.

Exclusion criteria were pregnancy or breast-feeding, creatinine levels higher than $1.5 \mathrm{mg} / \mathrm{dL}$, active infection or serious acute illness, known HIV, known malignancy, diabetes, liver function studies elevated to 3 times normal, hemoglobin levels lower than $8 \mathrm{~g} / \mathrm{dL}$, allergies to shellfish or intravenous contrast, estimated survival less than $1 \mathrm{y}$, and CD activity index (CDAI) greater than 450 , which is associated with severe disease (30). Patients who had a stoma created within $6 \mathrm{mo}$, who had any abdominal surgery within 3 mo of entry into the study, or who required emergency surgery were also excluded. The results of the study were not provided to the referring clinician and did not influence further therapeutic decisions.

Baseline laboratory data, including erythrocyte sedimentation rate (ESR) and C-reactive protein (CRP), were obtained. Baseline CDAI was determined, and each patient received a rating from 1 to 10 for the prediction of the relative degree of inflammation (1) through fibrosis (10) as part of the physician's global assessment (PGA) by the patients' gastroenterologists with expertise in inflammatory bowel disease (IBD) care.

\section{${ }^{18}$ F-FDG PET/CT Scans}

All patients underwent ${ }^{18} \mathrm{~F}$-FDG PET/CT before anticipated surgery. Patients fasted for a minimum of $4 \mathrm{~h}$ and had mean blood glucose levels of $88 \pm 14 \mathrm{mg} / \mathrm{dL}$ before the intravenous injection of a weight-based amount of ${ }^{18} \mathrm{~F}-\mathrm{FDG}(8.14 \mathrm{MBq} / \mathrm{kg}$ [mean, $592 \pm$ $148 \mathrm{MBq}])$. Oral water $(n=14)$ or $1.3 \%$ Readicat-diluted barium contrast material $(n=2)$ (E-Z-EM Inc.) was administered for the CT portion of the study. One patient could not tolerate any oral contrast material.

After an uptake phase of ${ }^{18} \mathrm{~F}-\mathrm{FDG}$ of approximately $60 \mathrm{~min}$, a combined PET/CT scan (Discovery LS; GE Healthcare) was obtained from the mid thorax through the pelvis. A non-contrastenhanced CT scan was obtained first, with a 4-slice multidetector helical scanner and the following parameters: $140 \mathrm{kVp}$, weightbased amperage (range, $40-160 \mathrm{~mA}$ ), $0.8 \mathrm{~s}$ per CT rotation, pitch of 1.5, and table speed of $22.5 \mathrm{~mm} / \mathrm{s}$. A CT transmission map was generated for image fusion. Emission data were acquired for $5 \mathrm{~min}$ at each bed position. PET images were reconstructed using the ordered-subset expectation maximization algorithm (2 iterations, 28 subsets), an 8 -mm gaussian filter with a $128 \times 128$ matrix, and CT attenuation correction. After the PET/CT scan, 8 patients also received $120 \mathrm{~mL}$ of Omnipaque 350 (GE Healthcare) and underwent venous phase (65- to 70-s delay) intravenous contrast-enhanced CT. Images were obtained from the mid thorax to the pelvis without moving the patient from the imaging table.

\section{Image Analysis}

All ${ }^{18} \mathrm{~F}-\mathrm{FDG}$ PET/CT and intravenous contrast-enhanced CT scans were reviewed in consensus by 2 readers with expertise in PET/CT on a Xeleris workstation (GE Healthcare). Patients' participation in the study of $\mathrm{CD}$ with obstruction was known, but the readers were unaware of other clinical information at the time of image interpretation. The PET/non-contrast-enhanced CT scan (PET/CT) was reviewed first, followed by the PET/intravenous contrast-enhanced CT scan (PET/CT $\left.\mathrm{P}_{\text {intravenous }}\right)(n=8)$.

Images were reviewed for lesions, defined as foci of ${ }^{18} \mathrm{~F}-\mathrm{FDG}$ uptake in the abdomen or pelvis potentially representing active inflammation of the bowel. Lesions were scored on a 5-point scale for diagnostic certainty ( 0 , definitely normal; 1 , probably normal; 2 , equivocal; 3 , probably abnormal; and 4 , definitely abnormal). A 3 -point scale for lesion localization was used (0, unknown; 1 , probable; and 2, definite). CT scans with intravenous contrast were considered to provide additional information to PET/CT images if they improved perceived diagnostic certainty for the presence or absence of active inflammation or localization of a lesion.

The secondary objectives of this study were to determine whether semiquantitative analyses of ${ }^{18} \mathrm{~F}-\mathrm{FDG}$ uptake could be used as a measure of inflammation. Single-pixel maximum standardized uptake value corrected for lean body mass $\left(\mathrm{SUL}_{\max }\right)$ was determined for lesions on PET/CT potentially representing active inflammation of the bowel. $\mathrm{SUL}_{\max }$ was not determined for lesions that were 
considered to ultimately represent physiologic findings on PET/CT. For those patients with more than 1 lesion on ${ }^{18} \mathrm{~F}-\mathrm{FDG}$ PET/CT, a representative lesion with the highest $\mathrm{SUL}_{\max }$ and best correlating with findings at surgery was chosen for further analysis.

Total lesion (tumor) glycolysis was previously described and reflects both tumor metabolism and size, and changes in total lesion glycolysis are potentially valuable for monitoring response of a tumor to therapy (31). Accordingly, we calculated total inflammatory volume (TIV) for each patient, hypothesizing that TIV might be more representative of a patient's overall inflammatory burden than single-pixel SUL $_{\text {max }}$.

On the basis of a technique used for total lesion glycolysis in colorectal cancer (32), TIV was calculated by the product of PETderived inflammatory volume ( PET $_{\text {inf-vol }}$ ) and the average SUL in the PET $_{\text {inf-vol }}$. The lesion of interest was first defined with 3-dimensional software tools available on the Advantage Workstation (GE Healthcare). Then, PET $_{\text {inf-vol }}$ was derived using a thresholding tool and the patient's average SUL in a $3-\mathrm{cm}$ region of interest in the liver as the lower limit of ${ }^{18} \mathrm{~F}-\mathrm{FDG}$ uptake.

For 8 patients with $\mathrm{PET} / \mathrm{CT}_{\text {intravenous }}$, average Hounsfield units (HU) were determined in a $1-\mathrm{cm}$ region of interest around a lesion's region of $\mathrm{SUL}_{\max }$ on the non-contrast-enhanced and contrast-enhanced CT scans. Percentage change in HU was determined by:

$$
\frac{\mathrm{HU} \text { PET } / \mathrm{CT}_{\text {intravenous }}-\mathrm{HU} \mathrm{PET} / \mathrm{CT}}{\mathrm{HU} \mathrm{PET} / \mathrm{CT}} \times 100 \%
$$

\section{Surgery}

All patients were expected to require surgery for obstructive symptoms and agreed to surgery on enrollment into the study. The decision to proceed with surgery was made by the gastroenterologist and surgeon on the basis of the patient's disease longevity and severity of obstructive symptoms, presence of clinical disease activity, and anatomic imaging findings and endoscopy. The entire bowel was examined intraoperatively and areas of stricture or obstruction assessed and resected.

The gastroenterologist and surgeon were unaware of the results of the PET/CT scans, unless unexpected extraabdominal findings were seen that might have emergently affected patient care. One patient had a 1.4-cm lung nodule with intense ${ }^{18} \mathrm{~F}-\mathrm{FDG}$ uptake, and pathology from wedge resection performed before bowel resection revealed granulomatous inflammation.

\section{Histopathology}

Slides were reviewed by 1 of 3 experienced gastrointestinal pathologists who were unaware of the results of the PET/CT scans, using a previously validated histopathologic scoring system developed as part of this protocol (results will be reported separately).

Surgical specimens were received fresh from the operating room and immediately processed according to previously published methods (33). Blocks, at least 1 per 5-cm length, were taken from all diseased areas, from resection margins, and from areas that appeared normal. All focal areas of narrowing were examined. A single slide from the thickest and most involved area of each individual block was analyzed.

Paraffin tissue sections were evaluated for the degree of inflammation with hematoxylin and eosin stains. The degrees of acute neutrophilic infiltration and chronic lymphoplasmacytic infiltration were scored as absent (0), mild (1), moderate (2), or severe
(3), based on the density and extent of inflammatory infiltrate and bowel-wall thickening seen. The global inflammation score was calculated as the sum of the acute and chronic inflammation scores.

Paraffin tissue sections were evaluated for collagen with trichrome staining for fibrosis scoring. The percentage of fibrosis involving the muscularis propria was determined in the most fibrotic affected area. Measurements (in 10\% increments) were made on the basis of the density, intensity, and extent of involvement.

The tissue sections were evaluated for muscle hypertrophy with hematoxylin and eosin stains. Morphometric measurements were obtained of the diameter of thickest hypertrophied muscularis propria and compared with the diameter of the normal-appearing muscularis propria in the same patient (i.e., hypertrophied muscularis propria diameter/normal muscularis propria diameter).

Finally, the predominant histopathologic subtype for each patient was determined by the pathologist as mainly inflammation, fibrosis, or muscle hypertrophy. The final predominant histopathologic subtype considered findings from the gross specimen and all 3 scoring evaluations (inflammation, fibrosis, and muscle hypertrophy).

\section{Statistics}

Kruskal-Wallis tests were used for the comparison of means. Correlations between $\mathrm{SUL}_{\max }$, TIV, percentage change in HU, and clinical data were performed using Pearson correlation coefficients and $z$ tests (Systat and Microsoft Excel software). $P$ values less than 0.05 were considered statistically significant.

Receiver-operating-characteristic curve (ROC) analysis was performed using JROCFIT software (http://www.rad.jhmi.edu/ jeng/javarad/roc/JROCFITi.html) to determine potentially optimal values of $\mathrm{SUL}_{\max }$ and TIV for accurately diagnosing active inflammation of the bowel.

\section{RESULTS}

Seventeen patients ( 9 women, 8 men; median age, $39 \mathrm{y}$; range, 26-63 y) with CD were enrolled. Demographics and baseline clinical and laboratory data are presented in Table 1. Six patients underwent surgery within $14 \mathrm{~d}$ of PET/CT (median, $28 \mathrm{~d}$; range, 2-148 d). Four patients recruited for the study underwent PET/CT but recovered from obstructive symptoms and did not require surgery.

\section{PET/CT Findings}

Thirty-three foci of increased ${ }^{18} \mathrm{~F}-\mathrm{FDG}$ uptake (lesions) in the abdomen that potentially represented active inflammation in the bowel were visualized on PET/CT. All 17 patients had at least 1 lesion (median, 2; range, 1-3). For the presence of active inflammation, diagnostic certainty scores were definitely abnormal (4) for 18 lesions, probably abnormal (3) for 5, equivocal (2) for 3 , probably normal (1) for 3 , and definitely normal (0) for 4 .

Considering the single lesion with the highest ${ }^{18} \mathrm{~F}-\mathrm{FDG}$ uptake per patient, the average $\mathrm{SUL}_{\max }( \pm \mathrm{SD})$ of potential active CD inflammatory lesions was $6.9 \pm 2.9$. The average TIV for all patients was $172 \pm 136 \mathrm{SUL} \cdot \mathrm{mL}$.

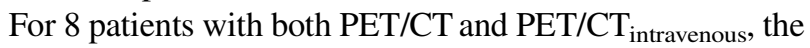
addition of intravenous contrast did not result in significant alterations of the PET/CT interpretation. The same 14 PET findings were seen on both PET/CT and PET/CT $\mathrm{P}_{\text {intravenous. }}$ 
TABLE 1. Demographics and Clinical and Laboratory Results

\begin{tabular}{|c|c|c|c|c|c|c|c|c|}
\hline $\begin{array}{c}\text { Patient } \\
\text { no. }\end{array}$ & Sex & $\begin{array}{c}\text { Age } \\
\text { (y) }\end{array}$ & $\begin{array}{l}\text { Duration of } \\
\text { Crohn's } \\
\text { disease }(y)\end{array}$ & PGA score* & $\mathrm{CDAl}^{+}$ & $\begin{array}{c}\text { ESR } \\
(\mathrm{mm} / \mathrm{h})\end{array}$ & CRP (mg/dL) & $\begin{array}{l}\text { Days between } \\
\text { PET/CT } \\
\text { and surgery }\end{array}$ \\
\hline 1 & $\mathrm{M}$ & 39 & 14.3 & 8 & 260 & 17 & 2.9 & 54 \\
\hline 2 & $\mathrm{~F}$ & 40 & 14 & 6 & 304 & 60 & 4.2 & 5 \\
\hline 3 & $\mathrm{~F}$ & 31 & 10 & 9 & 239 & 3 & NA & 28 \\
\hline 4 & $M$ & 41 & 18.25 & 6 & 198 & 27 & 2 & 2 \\
\hline 5 & $\mathrm{~F}$ & 52 & 5 & 7 & 218 & 9 & $<0.3$ & 8 \\
\hline 6 & $M$ & 31 & 23.5 & 8 & 195 & 24 & 0.7 & 64 \\
\hline 7 & $\mathrm{~F}$ & 32 & 10.75 & 8 & 173 & 15 & 3 & 6 \\
\hline 8 & $\mathrm{~F}$ & 57 & $>20$ & 7 & 102 & 41 & NA & 12 \\
\hline 9 & $M$ & 36 & 11.75 & 5 & 91 & 4 & $<0.3$ & 63 \\
\hline 10 & $\mathrm{~F}$ & 44 & 4 & 8 & 60 & 14 & 0.4 & 148 \\
\hline 11 & M & 26 & 10 & 6 & 212 & 9 & 1 & 42 \\
\hline 12 & $M$ & 33 & 3 & 7 & 261 & 9 & 0.3 & 52 \\
\hline 13 & M & 63 & 32 & 7 & 228 & 18 & 2.3 & 12 \\
\hline 14 & $M$ & 29 & 0.2 & 3 & 170 & 25 & 2.8 & No surgery \\
\hline 15 & $\mathrm{~F}$ & 59 & 4.3 & 7 & 200 & 52 & 1.3 & No surgery \\
\hline 16 & $\mathrm{~F}$ & 34 & $\sim 20$ & 6 & 296 & 13 & 0.5 & No surgery \\
\hline 17 & $\mathrm{~F}$ & 57 & $>11.58$ & 4 & 241 & 30 & 7 & No surgery \\
\hline \multicolumn{2}{|l|}{ Median } & 39 & 11.6 & 7 & 212 & 15 & 0.85 & 28 \\
\hline \multicolumn{2}{|l|}{ Range } & $26-63$ & $0.2-32$ & $3-9$ & $60-304$ & $3-64$ & $0.3-7$ & $2-148$ \\
\hline \multicolumn{9}{|c|}{$\begin{array}{l}{ }^{*} \text { Scale for predicting relative degree of inflammation (1) to fibrosis (10). } \\
{ }^{\dagger} \text { CDAI } \leq 150 \text {, inactive disease; } 150-450 \text {, active disease; } \geq 450 \text {, severe disease. } \\
\text { NA = not available. }\end{array}$} \\
\hline
\end{tabular}

Three diagnostic certainty scores increased from 3 to 4 , and there were no changes in any lesion localization certainty scores. Probably or definitely abnormal lesions on PET/CT localized to thickened bowel wall with mucosal and wall enhancement after intravenous contrast. The average percentage increase in HU of corresponding (to PET findings) bowel wall after intravenous contrast was $162 \% \pm 81 \%$ (range, 55\%-318\%).

\section{Pathologic Findings}

Twelve of 13 patients who underwent surgery had pathologic correlation (Table 2). The predominant histopathologic finding was inflammation in 5, fibrosis in 4 , and muscle hypertrophy in 3 . One patient (of 13) who underwent surgery had a bypass of the Crohn's stricture via a jejunojejunostomy rather than resection because of the finding of cryptogenic cirrhosis with ascites and a history of poor healing. Tissue for histopathology was not obtained in this patient, but at surgery a chronic stricture in the jejunum was found, resulting in dilation of proximal small bowel.

Some degree of acute inflammation was found in all patients ( $n=4$, mild; $n=2$, moderate; and $n=6$, severe). All patients also demonstrated chronic inflammation $(n=$ 1 , mild; $n=3$, moderate; and $n=8$, severe). All patients demonstrated muscle hypertrophy of the muscularis propria (median, 20-fold thickening; range, 9- to 40-fold thickening). The median percentage fibrosis of the muscularis propria was $50 \%$ (range, $40 \%-90 \%$ ).

\section{Correlation of PET/CT with Histologic Inflammation}

For PET/CT, 4 of 5 patients with predominantly active inflammation on histology were believed to have active inflammation (diagnostic certainty scores, 3 or 4). One patient had an equivocal diagnostic certainty score (2) for active inflammation. Moderate or severe acute and chronic inflammation was found on histopathology in all 5 patients with predominantly active inflammation.

Patients with severe chronic inflammation had significantly higher $\mathrm{SUL}_{\max }$ than those with mild or moderate chronic inflammation $(8.1 \pm 2.8$ vs. $4.7 \pm 2.5, P=0.04)$ but not higher TIV $(192 \pm 146$ vs. $161 \pm 182 \mathrm{SUL} \cdot \mathrm{mL}, P=$ 0.73). Examples are shown in Figures 1 and 2. On the basis of acute (Table 3) or global inflammation scores (data not shown), no significant differences in $\mathrm{SUL}_{\max }$ or TIV were observed.

\section{Accuracy of ${ }^{18}$ F-FDG PET/CT for Detecting Inflammation}

ROC curve analyses of PET semiquantitative analyses revealed cutoff values of 8.0 for SUL $_{\max }$ and 223.6 for TIV as optimal for distinguishing inflammation and fibrosis or hypertrophy in the bowel (Figs. 3 and 4). For SUL $\max$ greater than 8.0, the sensitivity for detecting active inflammation of the bowel was $60 \%$, specificity was $100 \%$, positive predictive value was $100 \%$, negative predictive value was $78 \%$, and accuracy was $83 \%$. For TIV greater than 223.6 , the sensitivity was $60 \%$, specificity was $71 \%$, positive predictive value was $71 \%$, negative predictive value was $60 \%$ and accuracy was $67 \%$. 


\begin{tabular}{|c|c|c|c|c|c|c|c|c|}
\hline \multirow{3}{*}{$\begin{array}{c}\text { Patient } \\
\text { no. }\end{array}$} & \multicolumn{5}{|c|}{ Pathology } & \multicolumn{3}{|c|}{ PET/CT } \\
\hline & \multicolumn{2}{|c|}{ Inflammation score } & \multicolumn{2}{|c|}{ Muscularis propria } & \multirow{2}{*}{$\begin{array}{l}\text { Predominant } \\
\text { subtype }\end{array}$} & \multirow{2}{*}{$\begin{array}{l}\text { Diagnostic } \\
\text { score }\end{array}$} & \multirow[b]{2}{*}{$\mathrm{SUL}_{\max }$} & \multirow{2}{*}{$\begin{array}{c}\text { TIV } \\
(\mathrm{SUV} \cdot \mathrm{mL})\end{array}$} \\
\hline & Acute & Chronic & Fibrosis (\%) & Hypertrophy & & & & \\
\hline 1 & 1 & 2 & 90 & $20 x$ & Fibrosis & 4 & 7.3 & 352.8 \\
\hline 2 & 3 & 3 & 50 & $10 x$ & Inflammation & 4 & 10.3 & 223.6 \\
\hline 3 & 1 & 1 & 50 & $9 x$ & Hypertrophy & 1 & 2.5 & 5.05 \\
\hline 4 & 3 & 3 & 50 & $15 x$ & Inflammation & 4 & 8.8 & 272.9 \\
\hline 5 & 2 & 3 & 60 & $10 x$ & Fibrosis & 4 & 7.2 & 24.9 \\
\hline 6 & 1 & 3 & 90 & $40 x$ & Hypertrophy & 4 & 8 & 85.9 \\
\hline 7 & 3 & 2 & 50 & $30 x$ & Inflammation & 2 & 2.7 & 5.30 \\
\hline 8 & 3 & 2 & 90 & $20 x$ & Fibrosis & 4 & 6.3 & 282.0 \\
\hline 9 & 3 & 3 & 50 & $30 x$ & Hypertrophy & 3 & 3.3 & 41.2 \\
\hline 10 & 1 & 3 & 60 & $30 x$ & Fibrosis & 4 & 7.6 & 160.3 \\
\hline 11 & 2 & 3 & 40 & $20 x$ & Inflammation & 3 & 6.9 & 465.8 \\
\hline 12 & 3 & 3 & 50 & $20 x$ & Inflammation & 4 & 13 & 258.2 \\
\hline $13^{*}$ & & & & & No pathology & 4 & 8.7 & 80.4 \\
\hline 14 & & & & & No surgery & 4 & 10.2 & 201.8 \\
\hline 15 & & & & & No surgery & 4 & 6.1 & 226.6 \\
\hline 16 & & & & & No surgery & 4 & 6 & 225.2 \\
\hline 17 & & & & & No surgery & 2 & 3.1 & 3.77 \\
\hline
\end{tabular}

No patient with an $\mathrm{SUL}_{\max }$ less than or equal to 8 was classified as having acute inflammation as their predominant histopathologic subtype. In 2 cases, acute inflammation was associated with an $\mathrm{SUL}_{\max }$ less than 8. In 1 patient (patient 11), the time between the PET scan and surgery was delayed to $42 \mathrm{~d}$ for work-up of hydronephrosis found incidentally on imaging. The cause of the low ${ }^{18} \mathrm{~F}$-FDG uptake in the second patient (patient 7) with predominantly inflammation remains unclear.

Sensitivity, specificity, and accuracy were not calculated on the basis of visual diagnostic certainty scores for the presence of active inflammation by PET and PET/CT because nearly all (8/12 on PET alone and 10/12 on PET/ CT) patients had scores of 3 or 4 (probably or definitely active inflammation).

For 14 lesions in the 8 patients with $\mathrm{PET} / \mathrm{CT}_{\text {intravenous, }}$ no significant correlations were found between percentage change in $\mathrm{HU}$ in the bowel wall after contrast and SUL $\max$ or TIV.

\section{Lack of Correlation of PET/CT with Predominant Histologic Pattern}

Seven patients had predominantly fibrosis or muscle hypertrophy on histology. Regardless, 6 of these 7 patients had

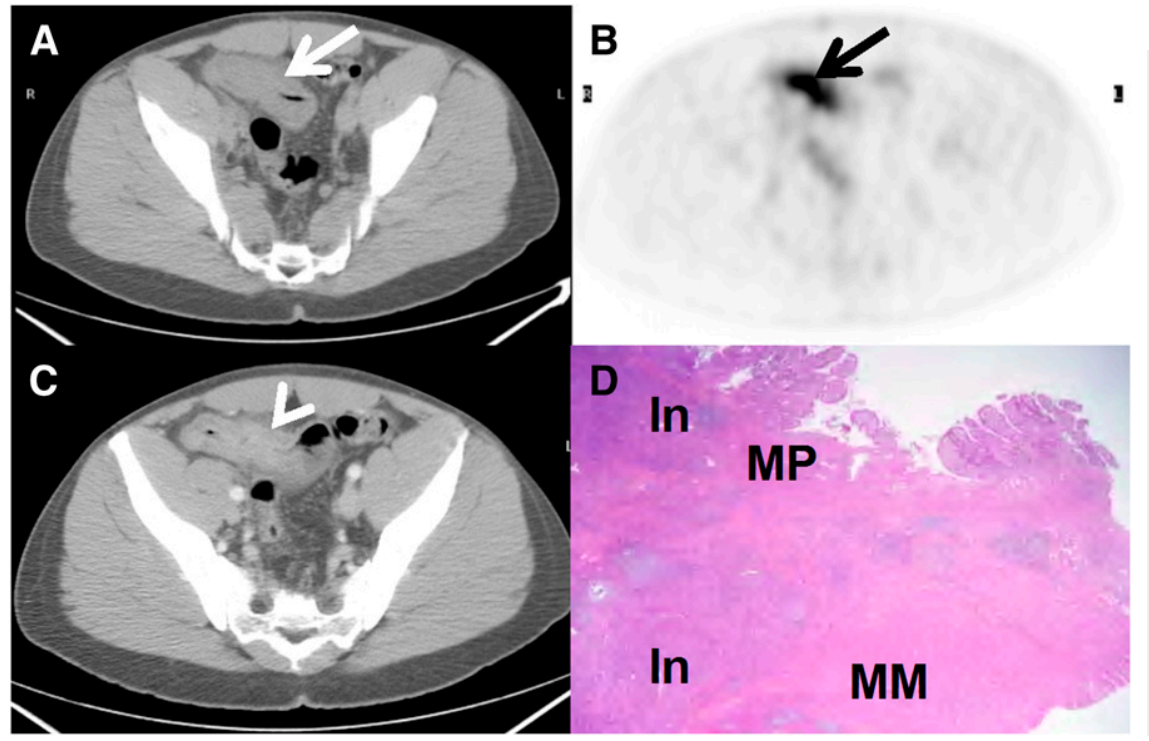

FIGURE 1. A 33-y-old man (patient 12) with CD for 3 y presented with cramps after eating. Small bowel series and CT scan showed marked thickening of distal ileum with luminal narrowing and proximal dilation of bowel. (A and $B$ ) $\mathrm{PET} / \mathrm{CT}$ revealed intense ${ }^{18} \mathrm{~F}-\mathrm{FDG}$ uptake fusing to thickened ileum (arrows). Diagnostic certainty score for active inflammation was 4 (definitely inflammation). SUL $\max$ was 13 , and TIV was 258.2 SUL.mL. (C) Intravenous contrastenhanced CT scan shows mural stratification (arrowhead). (D) In resected terminal ileum, there was acute and chronic transmural inflammation (In) and muscularis propria (MP) and muscularis mucosa (MM) hypertrophy and fibrosis. 
FIGURE 2. A 31-y-old woman (patient 3 ) with CD for $10 y$ and 3 prior small bowel obstructions presented with right lower quadrant pain and was diagnosed with recurrent partial small bowel obstruction. (A-C) PET/CT demonstrated small focus of ${ }^{18} \mathrm{~F}-\mathrm{FDG}$ uptake fusing to normalappearing distal small bowel on noncontrast-enhanced CT scan (arrows). Diagnostic certainty score was 1 (probably not inflammation), SUL $\max$ was 2.5 , and TIV was 5.1 SUL.mL. At ileocecectomy, terminal ileum and cecum were moderately indurated, and ileocecal area had narrow stenosis. (D) In resected terminal ileum, there was marked muscularis propria (MP) and muscularis mucosa (MM) hypertrophy and fibrosis but minimal acute or chronic inflammation.
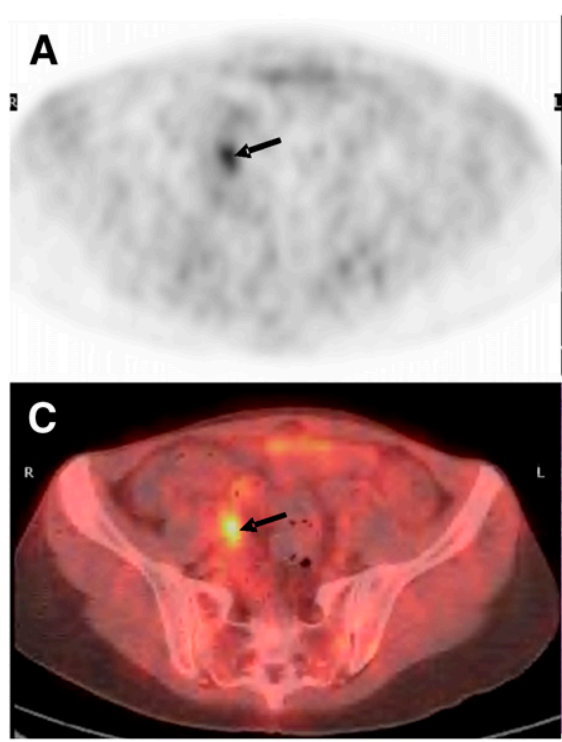

moderate or severe chronic inflammation and 3 had moderate or severe acute inflammation. Diagnostic certainty scores of 3 or 4 suggesting active inflammation were assigned to 6 patients by PET/CT. One patient had a predominant histopathologic subtype of muscle hypertrophy and had a score of 1 , suggesting the absence of active inflammation.

SUL $_{\text {max }}$ was not significantly different for patients with fibrosis or hypertrophy and inflammation $(6.0 \pm 2.2$ and $8.3 \pm$ $3.9, P=0.22$; Table 3 ). There were no significant differences in TIV between patients with fibrosis or hypertrophy and inflammation, though the mean for the inflammation group appeared higher $(136 \pm 135$ and $245 \pm 164 \mathrm{SUL} \cdot \mathrm{mL}, P=$ $0.37)$.

The number of days between the PET/CT scan and surgery tended to be longer in patients with fibrosis or hypertrophy than in those with inflammation $(52 \pm 52 \mathrm{~d}$ vs. $21 \pm 24 \mathrm{~d}$ ). The number of days between the PET/CT scan and surgery did not correlate with $\mathrm{SUL}_{\max }(r=0.04, P=$ $0.90)$ or TIV $(r=0.07, P=0.83)$.

\begin{tabular}{lcc}
\hline \multicolumn{3}{c}{ TABLE 3. Semiquantitative Analyses of ${ }^{18}$ F-FDG Uptake } \\
\hline \multicolumn{1}{c}{ Pathology } & SUL $_{\max }$ & TIV \\
Chronic inflammation & & \\
$\quad$ Mild, moderate $(n=4)$ & $4.7 \pm 2.5$ & $161 \pm 183$ \\
Severe $(n=8)$ & $8.1 \pm 2.8$ & $192 \pm 146$ \\
$P$ & 0.04 & 0.73 \\
Acute inflammation & $6.6 \pm 2.0$ & $182 \pm 187$ \\
$\quad$ Mild, moderate $(n=6)$ & $7.4 \pm 4.0$ & $180 \pm 124$ \\
Severe $(n=6)$ & 0.63 & 0.87 \\
$P$ & & \\
Predominant histopathology & $6.0 \pm 2.2$ & $136 \pm 135$ \\
Fibrosis or hypertrophy $(n=7)$ & $8.3 \pm 3.9$ & $245 \pm 164$ \\
Inflammation $(n=5)$ & 0.22 & 0.37 \\
$P$ & & \\
& & \\
Data mean \pm SD. & &
\end{tabular}

\section{Lesion Localization on PET/CT}

Lesion localization on ${ }^{18} \mathrm{~F}-\mathrm{FDG}$ PET/CT was compared with the location of the resected lesion at surgery for 18 lesions with a diagnostic certainty score greater than or equal to 1 . Two rectosigmoid lesions and a perianal fistula were not examined or resected at surgery. Seven lesions
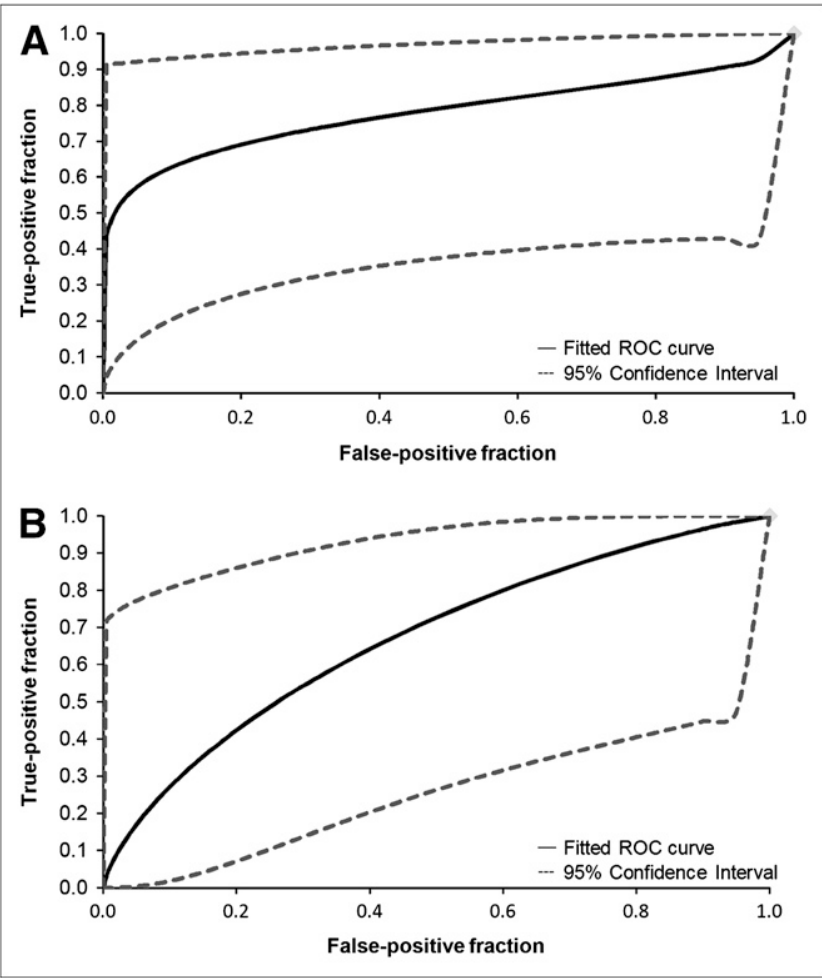

FIGURE 3. ROC curves of $\operatorname{SUL}_{\max }(\mathrm{A})$ and TIV (B). Area under curve for $\mathrm{SUL}_{\max }$ is 0.78 and 0.67 for TIV. On the basis of ROC analysis, optimal cutoff values yielding best diagnostic accuracy for presence of active inflammation in bowel

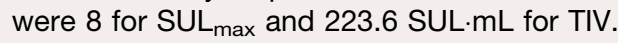




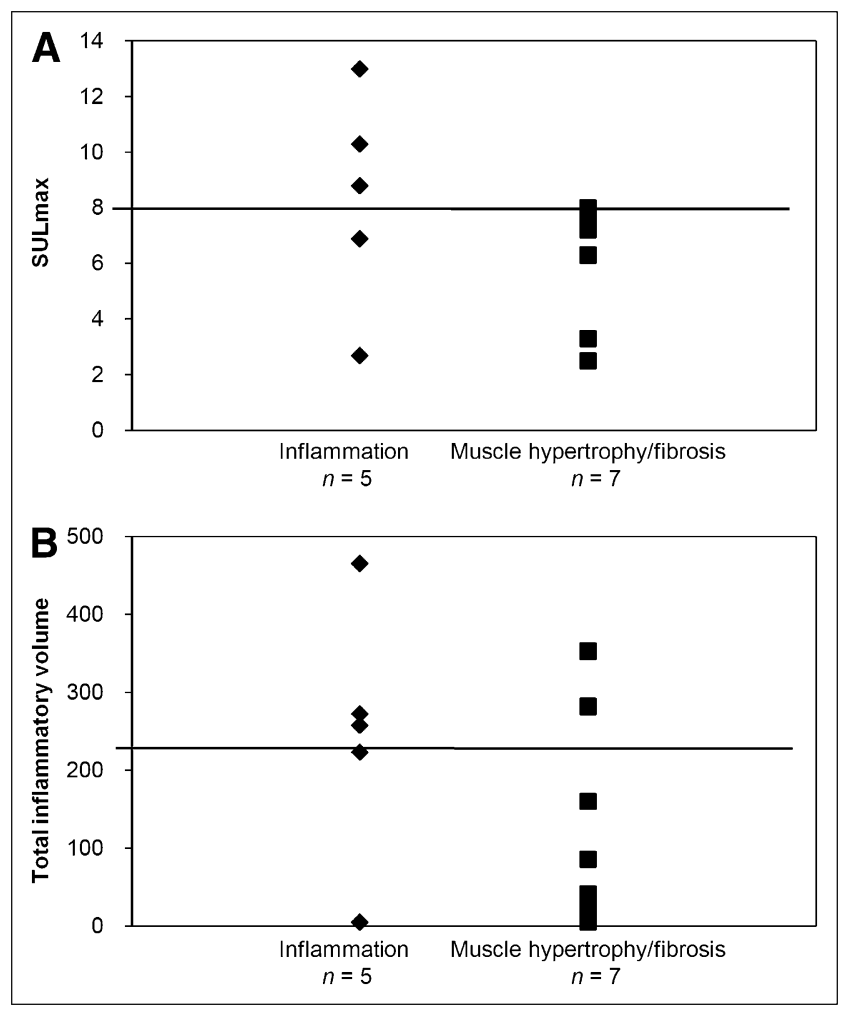

FIGURE 4. Correlation of $S_{\text {SUax }}(\mathrm{A})$ and TIV (B) for individual patients vs. predominant histopathologic subtype. Using cutoff value of 8.0 for SUL max $_{\text {max }}$ (line), sensitivity for detection of active inflammation of bowel was $60 \%$, specificity was $100 \%$, positive predictive value was $100 \%$, and negative predictive value was $78 \%$. Using 223.6 (line) as cutoff value for TIV, sensitivity was $60 \%$, specificity was $71 \%$, positive predictive value was $71 \%$, and negative predictive value was $60 \%$.

were correctly localized by ${ }^{18} \mathrm{~F}-\mathrm{FDG}$ PET/CT to the terminal ileum with or without cecal involvement. Seven lesions that involved the terminal ileum and cecum or ileocecal valve were localized to the distal small bowel only on ${ }^{18} \mathrm{~F}$-FDG PET/CT. One lesion that was localized to the ileocecal valve on ${ }^{18} \mathrm{~F}$-FDG PET/CT involved only the small bowel on resection.

\section{Lack of Correlation of Laboratory Data with Histology and PET/CT}

No significant correlations were found between clinical parameters (PGA, CDAI, ESR, or CRP) and $\mathrm{SUL}_{\max }$ or TIV. On the basis of predominant histopathologic subtype (fibrosis or hypertrophy vs. inflammation), there were no significant differences in PGA ( $7.4 \pm 1.3$ vs. $6.6 \pm 0.89, P=0.18)$, $\operatorname{CDAI}(166 \pm 80$ vs. $230 \pm 52, P=0.22), \mathrm{ESR}(16 \pm 13 \mathrm{~mm} / \mathrm{h}$ vs. $24 \pm 21 \mathrm{~mm} / \mathrm{h}, P=0.46)$, or CRP $(0.92 \pm 1.1 \mathrm{mg} / \mathrm{dL}$ vs. $2.1 \pm 1.6 \mathrm{mg} / \mathrm{dL}, P=0.17)$. The median CDAI score for the 12 patients with histopathology was 205 . Neither $\mathrm{SUL}_{\max }$ nor TIV was significantly different between those with a CDAI score less than 205 or greater than $205(6.1 \pm 2.6$ vs. $7.9 \pm$
$3.5, P=0.63$, and $141 \pm 118$ vs. $222 \pm 181, P=0.63$, respectively).

\section{DISCUSSION}

We compared the level of ${ }^{18} \mathrm{~F}-\mathrm{FDG}$ uptake on PET/CT to the histopathology of resected specimens of bowel from patients with $\mathrm{CD}$ and obstructive symptoms, hypothesizing that acute inflammatory lesions would accumulate more ${ }^{18} \mathrm{~F}$-FDG than would predominantly fibrotic strictures or muscle hypertrophy. Our results demonstrated that although ${ }^{18}$ F-FDG uptake correlates with the presence of inflammation in lesions of $\mathrm{CD}$, fibrotic strictures and muscle hypertrophy also accumulate ${ }^{18} \mathrm{~F}-\mathrm{FDG}$. Evaluation of the entire bowel wall via surgical specimens was a unique and crucial aspect of the present study for understanding the pathophysiology of the ${ }^{18} \mathrm{~F}$-FDG uptake in our patient population.

The inability of ${ }^{18} \mathrm{~F}$-FDG PET/CT to discriminate between predominantly active inflammatory lesions, fibrotic strictures, or muscle hypertrophy by visual interpretation alone was probably attributable to the continuum of both acute and chronic inflammatory cells in all patients' specimens. The primary leukocytes in both acute and chronic inflammation (neutrophils and macrophages, respectively) are well known to accumulate high levels of ${ }^{18}$ F-FDG (2022). Patients with severe chronic inflammation had significantly higher SULs than those with mild or moderate inflammation, supporting the mechanistic aspects of PET in active inflammation.

Another plausible explanation for our high false-positive rate by visual interpretation is a contribution of ${ }^{18} \mathrm{~F}-\mathrm{FDG}$ uptake by contracting or hypertrophied smooth muscle in the bowel wall. The foci of increased ${ }^{18} \mathrm{~F}$-FDG uptake considered representative of active inflammation localized mostly to the bowel wall, not intraluminally, on the coregistered CT scan, and substantial muscle hypertrophy was seen in all histopathologic specimens. Previous attempts to elucidate the precise etiology of ${ }^{18} \mathrm{~F}-\mathrm{FDG}$ uptake by the bowel were limited and yielded mixed results, but several authors reported decreased ${ }^{18} \mathrm{~F}$-FDG uptake in the bowel after the administration of antiperistaltic agents, at least suggesting a smooth muscle component $(34,35)$.

Semiquantitative analyses of ${ }^{18} \mathrm{~F}-\mathrm{FDG}$ uptake helped distinguish predominantly active inflammation from fibrotic strictures and muscle hypertrophy. An SUL $\max$ cutoff of 8 seemed to be most accurate. The higher (but not statistically significant) mean TIV in predominantly active inflammation suggests the possibility that this parameter is also informative, but TIV was considerably variable. This higher mean TIV may reflect a bias toward inflammation in all patients in this study. The relatively small number of patients in whom histology was obtained limits the statistical power of this observation.

Interestingly, patients with predominantly active inflammation, compared with those with predominantly fibrosis or 
muscle hypertrophy, underwent surgery closer to the time of PET/CT. These patients may have clinically been more symptomatic, requiring surgery sooner. By the time of surgery, some component of active inflammation visualized on ${ }^{18}$ F-FDG PET/CT could have partially resolved for those with predominantly fibrosis or muscle hypertrophy.

Several studies have suggested that ${ }^{18}$ F-FDG PET and PET/CT in adult and pediatric patients, compared with standard endoscopy, histology, radiography, and small bowel imaging, are useful for identifying active IBD (15,23-28). Sensitivities for this purpose have been reported to range from $54 \%$ to $98 \%$, with specificities from $55 \%$ to $81 \%$ (15,23-28). In general, these studies were limited because they did not provide a full evaluation of the entire bowel wall, and CD lesions are characteristically transmural.

In a prospective study of 22 patients with $\mathrm{CD}$, Louis et al. (26) reported an overall sensitivity of $72.9 \%$ and a specificity of $54.2 \%$ for detecting active CD lesions in 95 bowel segments evaluated by ${ }^{18} \mathrm{~F}-\mathrm{FDG}$ PET/CT and endoscopy performed for medical reasons. ${ }^{18} \mathrm{~F}-\mathrm{FDG}$ PET was $100 \%$ sensitive for the detection of severe lesions (deep ulcers and strictures). We also observed increased ${ }^{18}$ F-FDG uptake in fibrosis or hypertrophy and found some type of intestinal pathology that correlated with the need for surgery in all of our patients. Differentiation between stricture and acute inflammation was not attempted in the study by Louis et al. (26).

Numerous studies have demonstrated that increased leukocyte accumulation in active IBD correlates well with disease extent and severity in $\mathrm{CD}$, compared with endoscopy, histology, and fecal excretion of ${ }^{111}$ In-leukocytes (10-19). For inpatients with symptoms of small bowel obstruction (a population somewhat similar to ours, though probably with more severe active disease because $76 \%$ of our patients were outpatients) and positive enteroclysis, a negative ${ }^{111}$ In-leukocyte scan was reported to be suggestive of chronic fibrostenotic stricture, not acute inflammatory disease, due to lack of response to medical therapy (18).

The existence of the noninflamed stricture has recently been challenged. In 48 patients with $\mathrm{CD}, 31$ of 34 bowel strictures were positive for inflammation on histopathology from laparotomy, and $25(74 \%)$ of these were positive on leukocyte scintigraphy (11). In pathologic specimens collected at our institution, CD strictures had a mean inflammatory score of 2.3 (maximum inflammation score, 3 ), with $83 \%$ demonstrating at least moderate inflammation and $47 \%$ having severe inflammation (Theodore M. Bayless, unpublished data, 2006). Our data further support these findings.

We did not find any significant correlations between any of the clinical parameters (PGA, CDAI, ESR, CRP) and SUL $_{\text {max }}$ or TIV for predicting the presence of fibrosis or hypertrophy versus inflammation. This is in concordance with the findings of some authors $(11,15)$ but not others $(23,26)$. It is possible that the smaller range of CDAI scores in our patient population (60-304) was not large enough to show differences in ${ }^{18} \mathrm{~F}$-FDG uptake based on this param- eter. Also, obstructive rather than active disease symptoms led to inclusion in the current study. In a study including 176 patients with CD, CRP level at diagnosis was not found to be associated with location and biologic behavior of disease, but higher CRP levels were associated with increased risk for surgery in the subgroup with disease in the terminal ileum (36).

CT enterography or enteroclysis may have a role in determining whether small bowel narrowing is due to active inflammation (6-9). On CT enteroclysis, active inflammation is suggested by mural and wall enhancement, mural stratification, lymphadenopathy, engorgement of vessels, and wall thickness; fibrostenotic strictures, however, are associated with nonenhancing wall thickening, proximal dilation, and luminal stenosis (6). We did not apply semiquantitative or qualitative criteria for reading the intravenous contrast-enhanced CT scans as done in other studies (6-9).

Limitations of this study were the small study population and the readers' knowledge of the patients' diagnosis of CD and participation in the study. These factors could have biased the readers to be more sensitive to the detection of any abnormal ${ }^{18}$ F-FDG uptake in the bowel, which is often variable. No patients without CD were included as controls. However, the lack of a control group probably did not alter the results for the specific question being addressed in this study (fibrosis or hypertrophy vs. inflammation in patients with $\mathrm{CD}$ and obstructive symptoms) but limited determination of true specificity for detection of CD by ${ }^{18} \mathrm{~F}-\mathrm{FDG}$ PET/ CT. The exact correlation between the location of lesions visualized on PET/CT and resected at surgery was difficult, and standardization of pathology remains a challenge.

Finally, the lack of correlation between the predominant histopathologic subtype and established clinical markers of active inflammation at least raises the question of the validity of "predominant histopathologic subtype" as the gold standard. This study demonstrates that there is most likely a continuum of multiple processes involved in the etiology of luminal narrowing in patients with CD.

\section{CONCLUSION}

Patients with CD who undergo surgery for obstructive symptoms have histopathologically mixed findings of inflammation, fibrosis, and muscle hypertrophy. ${ }^{18} \mathrm{~F}-\mathrm{FDG}$

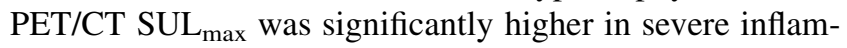
mation. Although qualitative PET interpretations using our scale appeared to be too sensitive for detection of inflammation, semiquantitative analyses using $\mathrm{SUL}_{\max }$ helped identify patients with predominantly active inflammation. This information may be helpful for referring gastroenterologists considering surgery versus medical therapy for patients with CD who present with obstructive symptoms. Further studies in larger patient populations are needed and could also examine the role of PET/CT in assessing the efficacy of medical management in treating IBD. 


\section{ACKNOWLEDGMENTS}

We thank Judy Buchanan and Donna Rode for their assistance in the preparation of this manuscript. Support for this study was provided by the Broad Medical Research Program, grant BMRP IBD-0122R.

\section{REFERENCES}

1. Crawford JM. The gastrointestinal tract. In: Cotran RS, Kumar V, Robbins SL, eds. Pathologic Basis of Disease. 5th ed. Philadelphia, PA: WB Saunders Company; 1994:755-830.

2. Gilberts EC, Greenstein AJ, Katsel P, Harpaz N, Greenstein RJ. Molecular evidence for two forms of Crohn disease. Proc Natl Acad Sci USA. 1994; 91:12721-12724.

3. Greenstein AJ, Lachman P, Sachar DB, et al. Perforating and non-perforating indications for repeated operations in Crohn's disease: evidence for two clinical forms. Gut. 1988;29:588-592.

4. Louis E, Collard A, Oger AF, Degroote E, Aboul Nasr El Yafi FA, Belaiche J. Behaviour of Crohn's disease according to the Vienna classification: changing pattern over the course of the disease. Gut. 2001;49:777-782.

5. Schwartz JF, Bayless TM, Hamilton SR. Crohn's disease: is there a predictable pattern of late ileal complications [abstract]? Gastroenterology. 1986;90:1623.

6. Chiorean MV, Sandrasegaran K, Saxena R, Maglinte DD, Nakeeb A, Johnson CS. Correlation of CT enteroclysis with surgical pathology in Crohn's disease. Am J Gastroenterl. 2007;102:2541-2550.

7. Hassan C, Cerro P, Zullo A, Spina C, Morini S. Computed tomography enteroclysis in comparison with ileoscopy in patients with Crohn's disease. Int J Colorectal Dis. 2003;18:121-125.

8. Higgins PD, Caoili E, Zimmermann M, et al. Computed tomographic enterography adds information to clinical management in small bowel Crohn's disease. Inflamm Bowel Dis. 2007;13:262-268.

9. Rollandi GA, Curone PF, Biscaldi E, et al. Spiral CT of the abdomen after distention of small bowel loops with transparent enema in patients with Crohn's disease. Abdom Imaging. 1999;24:544-549.

10. Brignola C, Belloli C, Iannone $\mathrm{P}$, et al. Comparison of scintigraphy with indium111 leukocyte scan and ultrasonography in assessment of x-ray-demonstrated lesions of Crohn's disease. Dig Dis Sci. 1993;38:433-437.

11. Almer S, Granerus G, Strom M, et al. Leukocyte scintigraphy compared to intraoperative small bowel enteroscopy and laparotomy findings in Crohn's disease. Inflamm Bowel Dis. 2007;13:164-174.

12. Arndt JW, van der Sluys Veer A, Blok D, et al. Prospective comparative study of technetium 99m-WBCs and indium-111-granulocytes for the examination of patients with inflammatory bowel disease. J Nucl Med. 1993;34:1052-1057.

13. Biancone L, Schillaci O, Capoccetti F, et al. Technetium-99m-HMPAO labeled leukocyte single photon emission computerized tomography (SPECT) for assessing Crohn's disease extent and intestinal infiltration. Am J Gastroenterol. 2005; $100: 344-354$

14. Lachter J, Isseroff HN, Yasin K, Keidar Z, Israel O. Radiolabeled leukocyte imaging in inflammatory bowel disease: a prospective blinded evaluation. Hepatogastroenterology. 2003;50:1439-1441.

15. Neurath MF, Vehling D, Schunk K, et al. Noninvasive assessment of Crohn's disease activity: a comparison of ${ }^{18} \mathrm{~F}$-fluorodeoxyglucose positron emission tomography, hydromagnetic resonance imaging, and granulocyte scintigraphy with labeled antibodies. Am J Gastroenterol. 2002;97:1978-1985.

16. Sans M, Fuster D, Llach J, et al. Optimization of technetium-99m-HMPAO leukocyte scintigraphy in evaluation of active inflammatory bowel disease. Dig Dis Sci. 2000;45:1828-1835.

17. Saverymuttu SH, Camilleri M, Rees H, Lavender JP, Hodgson HJ, Chadwick VS. Indium 111-granulocyte scanning in the assessment of disease extent and disease activity in inflammatory bowel disease: a comparison with colonoscopy, histology, and fecal indium 111-granulocyte excretion. Gastroenterology. 1986;90:11211128 .

18. Slaton GD, Navab F, Boyd CM, Diner WC, Texter EC Jr. Role of delayed indium111 labeled leukocyte scan in the management of Crohn's disease. Am J Gastroenterol. 1985;80:790-795.

19. Weldon MJ, Masoomi AM, Britten AJ, et al. Quantification of inflammatory bowel disease activity using technetium-99m HMPAO labelled leucocyte single photon emission computerised tomography (SPECT). Gut. 1995;36:243-250.

20. Mochizuki T, Tsukamoto E, Kuge Y, et al. FDG uptake and glucose transporter subtype expressions in experimental tumor and inflammation models. $\mathrm{J} \mathrm{Nucl}$ Med. 2001;42:1551-1555.

21. Sugawara Y, Braun DK, Kison PV, Russo JE, Zasadny KR, Wahl RL. Rapid detection of human infections with fluorine-18 fluorodeoxyglucose and positron emission tomography: preliminary results. Eur J Nucl Med. 1998;25:1238-1243.

22. Yamada S, Kubota K, Kubota R, Ido T, Tamahashi N. High accumulation of fluorine 18-fluorodeoxyglucose in turpentine-induced inflammatory tissue. $J$ Nucl Med. 1995;36:1301-1306.

23. Bicik I, Bauerfeind P, Breitbach T, von Schulthess GK, Fried M. Inflammatory bowel disease activity measured by positron-emission tomography. Lancet. 1997;350:262.

24. Lemberg DA, Issenman RM, Cawdron R, et al. Positron emission tomography in the investigation of pediatric inflammatory bowel disease. Inflamm Bowel Dis. 2005;11:733-738.

25. Loffler M, Weckesser M, Franzius C, Schober O, Zimmer KP. High diagnostic value of ${ }^{18} \mathrm{~F}$-FDG-PET in pediatric patients with chronic inflammatory bowel disease. Ann N Y Acad Sci. 2006;1072:379-385.

26. Louis E, Ancion G, Colard A, Spote V, Belaiche J, Hustinx R. Noninvasive assessment of Crohn's disease intestinal lesions with ${ }^{18} \mathrm{~F}-\mathrm{FDG}$ PET/CT. J Nucl Med. 2007;48:1053-1059.

27. Meisner RS, Spier BJ, Einarsson S, et al. Pilot study using PET/CT as a novel, noninvasive assessment of disease activity in inflammatory bowel disease. Inflamm Bowel Dis. 2007;13:993-1000.

28. Skehan SJ, Issenman R, Mernagh J, Nahmias C, Jacobson K. ${ }^{18}$ F-fluorodeoxyglucose positron tomography in diagnosis of paediatric inflammatory bowel disease. Lancet. 1999;354:836-837.

29. Gasche C, Scholmerich J, Brynskov J, et al. A simple classification of Crohn's disease: report of the Working Party for the World Congresses of Gastroenterology, Vienna 1998. Inflamm Bowel Dis. 2000;6:8-15.

30. Best WR, Becktel JM, Singleton JW, Kern F Jr. Development of a Crohn's disease activity index. National Cooperative Crohn's Disease Study. Gastroenterology. 1976;70:439-444.

31. Larson SM, Erdi Y, Akhurst T, et al. Tumor treatment response based on visual and quantitative changes in global tumor glycolysis using PET-FDG imaging: the visual response score and the change in total lesion glycolysis. Clin Positron Imaging. 1999;2:159-171.

32. Melton GB, Lavely WC, Jacene HA, et al. Efficacy of preoperative combined 18 fluorodeoxyglucose positron emission tomography and computed tomography for assessing primary rectal cancer response to neoadjuvant therapy. J Gastrointest Surg. 2007;11:961-969.

33. Kelly JK, Sutherland LR. The chronological sequence in the pathology of Crohn's disease. J Clin Gastroenterol. 1988;10:28-33.

34. Stahl A, Weber WA, Avril N, Schwaiger M. Effect of $N$-butylscopolamine on intestinal uptake of fluorine-18-fluorodeoxyglucose in PET imaging of the abdomen. Nuklearmedizin. 2000;39:241-245.

35. Emmott J, Sanghera B, Chambers J, Wong WL. The effects of $N$-butylscopolamine on bowel uptake: an ${ }^{18}$ F-FDG PET study. Nucl Med Commun. 2008;29: $11-16$.

36. Henriksen M, Jahnsen J, Lygren I, et al. C-reactive protein: a predictive factor and marker of inflammation in inflammatory bowel disease-results from a prospective population-based study. Gut. 2008;57:1518-1523. 